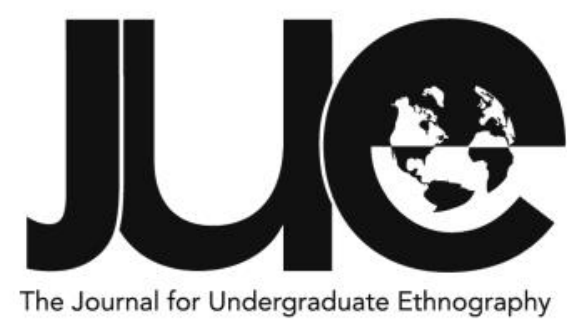

\title{
Dying Professions: Exploring Emotion Management among Doctors and Funeral Directors
}

Molly Ryan

Dalhousie University, molly.ryan@dal.ca

\section{ABSTRACT}

There are few more emotive experiences in life than death. Drawing on Arlie Hochschild's concept of emotional labour, this article compares the emotional responsibilities of two groups of death professionals: doctors and funeral directors. It addresses the lack of comparative studies in the otherwise robust literature concerning emotional labour in the workforce. Through qualitative analysis, I identify how funeral directors and doctors believe they should feel in regard to death, how they manage these feelings, and the related consequences of this emotional labour. This analysis suggests that the emotion management of these professionals is primarily influenced by two key factors: prioritizing the emotions of others and stifling one's own strong emotions. Differences became apparent in terms of how these factors are managed and what the related emotional consequences may be, due to the respective reliance of the funeral directors on surface acting and the doctors on deep acting emotion management strategies. In the future, it would be helpful to complement existing research with participant observation studies in order to better illuminate the meaning that emotional labour has for individuals in practice. Due to their unique position of encountering death as part of a job, death professionals have much to teach each other, as well as the broader population, about accepting and managing emotions related to mortality.

Keywords: emotional labour, death attitudes, emotion management, surface acting, deep acting 
ike death, emotions are inseparable from the human experience (Glomb and Tews 2004). Our worldviews are discovered and derived from feeling (Hochschild 1983). Studying emotional experience in the workplace sheds light on the social-psychological processes related to wellbeing in the modern North American economy and society as a whole (Wharton 2009). Emotion management studies in particular can help craft effective interventions to prevent the negative consequences associated with emotional labour (Bianchi et al. 2014; Hochschild 1983). For instance, funeral directors and doctors encounter death from unique perspectives; in crude terms, for doctors, death is loss, whereas for funeral directors, it is gain. Doctors are committed to the healing process and in many fields of medicine dying patients threaten their defined role, leading to feelings of failure and inadequacy (Auger 2007; Palgi and Abramovitch 1984; Strazzari 2005). In contrast, for funeral directors, death signifies business; it is both expected and relied upon. These contrasting perspectives may shape how doctors and funeral directors conceptualize death, which could in turn affect how they form their emotion management strategies. Thus, strategies from one profession may provide insight into skills that could be used by the other.

This article investigates how frequent workplace encounters with death shape the emotion management of doctors and funeral directors. Drawing on semi-structured interviews, I explore the day-to-day emotion management strategies and death attitudes of funeral directors and doctors practicing in various subfields. A qualitative analysis of this material allows me to identify the tacit rules that dictate how funeral directors and doctors should respectively feel in regard to death. I discuss three broad themes that arose from my findings: i) emotional labour in professional death experiences; ii) the feeling rules that govern this emotional labour; and iii) the related consequences of this emotional labour. This study is grounded in two key areas of literature: emotional labour and contemporary North American death attitudes.

\section{Emotional Labour in the Workplace}

Emotions help anchor one's sense of self, and act as a signal function; that is, they provide 'feeling clues' that give individuals an idea of how to respond to a given situation (Hochschild 1983). For instance, the feeling of being frightened signals an appropriate response, such as screaming, leaving or hiding. An organismic model of emotion argues that this emotional response is biological and innate (Ekman 1982; Hochschild 1983). However, a purely instinctual view of emotion fails to explain how people come to assess, label, and manage emotions (Ekman 1982). Hochschild's (1983) definition of emotion urges us to acknowledge the reflexive quality of emotions, arguing that the act of managing emotion is also a part of what the emotion becomes. This is supported by Thoits (1989), who asserts that the key determinants of emotional experience are sociocultural rather than biologically innate. The social nature of emotional responses has been well-studied in anthropology, with evidence of cross-cultural variability in both emotions and emotional expression (Ekman 1982; Peterson 2004; Thoits 1989).

Emotion management is the act of inducing or suppressing feeling in order to sustain the socially accepted and expected emotional response. In an applied context, this can be recognized as "acts upon feeling"; for example, trying to fall in love, letting yourself feel sad, or keeping your anger in check (Hochschild 1983, 13). Emotional labour more specifically highlights the laborious nature of this management; it does not come naturally, it is emotion work. In the workplace, emotional labour speaks to the processes by which feelings must be managed in accordance with organizational rules and expectations 
(Hochschild 1983; Wharton 2009). It underlines the fact that emotions are not only shaped by cultural norms, they are increasingly regulated and shaped by employers (Wharton 2009). Although this study refers to emotional labour in the workplace, emotional labour is also applicable to emotion work in other spheres; for instance, the gendered division of emotional labour in home life, such as the traditional expectation upon women to perform a greater proportion of "emotional" tasks and responsibilities, notably childcare (Hochschild 1983; Peterson 2004).

Emotional labour is informed and regulated by 'feeling rules' which address the proper extent, direction and duration of a feeling in a given situation (Hochschild 1979; Wharton 2009). For instance, feeling rules might indicate that one can feel too much or too little, feel happy when one should feel sad, or feel sad for too long. Feeling rules are recognized most easily when one is acting against them, or in other words, when what one feels does not match what 'should' be felt (Hochschild 1983).

In order to adhere to feeling rules, people rely upon various emotion management strategies. For Hochschild (1983), two are of primary concern: surface acting and deep acting. Surface acting is a display of emotion with no internal change; it is convincing to others but does not deceive the actor himself or herself (Hochschild 1983). Deep acting involves a transformation of the actor's own emotions to fit the situation and can involve directly exhorting feeling (e.g. psyching yourself up, 'you got this!') or retraining the imagination, akin to method acting (Hochschild 1983). Since these two strategies are abstract, it can prove difficult to articulate their use in an explicit manner. One way to determine how and why people employ these strategies is to identify clear examples of how they deal with emotional situations in their daily lives (Hochschild 1983).

Concrete applications of emotion management strategies for funeral directors and doctors include the use of humour (Hochschild 1983; Smith and Kleinman 1989; Mann 2004; Laudermilk 2012), or physical manipulation of emotionally laborious situations, such as members of either profession covering a corpse's hands, face and genitalia whenever they work with it for a long time during autopsies or embalming, for example (Smith and Kleinman 1989; Auger 2007; Laudermilk 2012). Approaching death scientifically rather than emotionally is also prevalent in the medical profession (Hochschild 1983; Smith and Kleinman 1989). In their study of medical students, Smith and Kleinman (1989) found that by competing for the highest grades, medical students develop the ability to separate feelings from content/context, instead focusing on impersonal facts. This disconnect, identified as scientific objectivity by its practitioners, functions as an effective emotion management mechanism. This orientation may extend to funeral directors, as they are educated in mortuary science, and are thus also fluent in a biomedical dialect that endorses the disconnect of a supposedly objective orientation.

One risk of emotional labour is that it "draws on a sense of self that we hono[u]r as deep and integral to our individuality" (Hochschild 1983, 7). When it is exploited, as it can be in the work setting, one can potentially become alienated from this vital part of oneself. The negative consequences of emotional labour are often a result of emotional dissonance, which occurs when the emotion one is expected to display is in direct opposition to what one feels on a personal level (Hochschild 1983; Glomb and Tews 2004; Wharton 2009; Dijk and Brown 2006). It can lead to a sense of selfestrangement due to the deep connection between emotion and self-concept (Wharton 2009). Workers who regularly display emotions that conflict with their true feelings are more likely to experience emotional exhaustion or burnout (Brotheridge and Grandey 2002; Mann 2004; Wharton 2009; Dijk and Brown 2006).

There is debate over whether emotional dissonance is a consequence of emotional labour (Wharton 2009) or an inherent component of it (Dijk and Brown 2006; Mann 2004). Mann (2004) believes that genuinely felt emotions, such as those achieved through deep acting, do not qualify as emotional labour. This is supported by findings that link emotional dissonance with surface acting more than deep acting (Wharton 2009). Thus, deep acting should still be considered emotional labour, but it is possible that its negative effects are not 
well-described by theories of emotional dissonance.

Many employees working in jobs requiring high amounts of emotional labour work under "emotion supervisors" who enforce expected feeling rules. For instance, flight attendants may be chastised by their supervisors if they are not sufficiently friendly with passengers (Hochschild 1983). Professionals who do not work with "emotion supervisors" immediately at hand have the autonomy to regulate their own emotional behaviour (Hochschild 1983; Smith and Kleinman 1989). They are therefore considered "privileged emotion managers," as having such emotional autonomy can offset the negative effects of emotional labour (Wharton 2009, 152; Hochschild 1983; Mann 2004).

Further, identifying strongly with one's social role can also serve as an anchor to offset the negative effects of emotional labour (Sloan 2007; Goffman 1959). Those with an established social role often feel more comfortable adhering to its associated feeling rules (Hochschild 1983). Thus, rather than feeling alienated from the societal whole, embracing their occupational roles as integral parts of their identity may allow these professionals to both accept and embrace death in a way most cannot without suffering from emotional burnout.

\section{Death Denial in North America}

There are few more emotive experiences in North American life than death. Contemporary death attitudes are often characterized by fear, guilt and death denial (Auger 2007). This discomfort can manifest as an avoidance of dying persons, avoidance of the bereaved, a fear of death and a feeling of uncertainty about an afterlife (Palgi and Abramovitch 1984; Aries 1974). As a result, the living are actively separated from the dead and death is met with ambivalence (Aries 1982; Auger 2007; Palgi and Abramovitch 1984; Strazzari 2005). This ambivalent attitude can be reflected in the experience of simultaneous love for the dead person and fear of the corpse (Palgi and Abramovitch 1984). Although this orientation towards death has been linked to the decline of religion and rise of secularism, secularism itself is not at fault; rather researchers blame this shift on the lack of a sufficient replacement for religion (Mellor and Shilling 1993). Without a way to situate their mortality, for many, death in the modern context has become confusing and isolating (Mellor and Shilling 1993). Due to their routine professional relationship with death, funeral directors and doctors become exceptions to this rule and thus interesting cases to study in order to attain a greater understanding of the societal taboos and attitudes towards death in the 21st century (Freud 1955).

According to previous studies, death has replaced sex as the ultimate "unmentionable", giving rise to a phenomenon Gorer (1955) coined the "pornography of death." This term is particularly useful as it not only implies death's taboo status, it also captures the following nuance: prevalent media portrayals of death mean that the average American TV-viewing child will see 10,000 depictions of death by the time they reach age 13 (Auger 2000, 21); while this statistic is somewhat dated, widespread access to media on demand and violent video games suggest that the number is likely to have increased. Further, these deaths are viewed in a context typically devoid of feelings, suffering and grief (Auger 2000). This has interesting implications for the expected emotional response to death for both the mainstream lay population and "death professionals" like funeral directors and doctors.

Doctors have been shown to have a clinical and impersonal attitude towards death that is both justified and cultivated in their professional training (Hochschild 1983). Students are rewarded for analyzing and reporting information about death and dying in a succinct, unemotional manner (Smith and Kleinman 1989). Dissecting cadavers is particularly important in shaping this attitude (Smith and Kleinman 1989; Laudermilk 2012). This is well-illustrated by Smith and Kleinman (1989), who noted that students managed uncomfortable initial experiences with cadavers by transforming the body into a non-human object; for instance, "[The pelvic exam] is pretty much like checking a toaster. It isn't a problem. I'm good at that kind of thing" (61).

Death may end a physical life, but it does not sever the social relationships that characterize 
human experience (Auger 2007). Funerals are symbolic rituals that artfully display the transformation from life to death and honour these social ties (Auger 2007). Funeral directors are the gatekeepers of this ritual and may be considered "ritual specialists" (Palgi and Abramovitch 1984). One socially significant quality of the funeral service, in terms of how it reflects modern death attitudes, is that it makes the intolerable - death - tolerable (Auger 2007). Anthropologists - for example, Turner (1969) have long emphasized the socially restorative functions of funeral rites and other deathrelated practices. Cross-cultural analysis reveals a wide range of these behaviours and practices, all of which serve as cultural expressions of unique value systems (Palgi and Abramovitch 1984).

Drawing from the above literature, I will be exploring the emotional labour of these death professionals and the related feeling rules (Hochschild 1983) that dictate how doctors and funeral directors believe they should feel about death. I will also make use of the concepts of surface acting, deep acting, and emotional dissonance to elucidate the complexities of emotional labour's consequences. Contextualized by the unique relationships doctors and funeral directors have towards death compared to the death denial identified in the above literature, this project deepens our understanding of professional emotional expectations and the lived experience of emotional labour as a required aspect of one's job.

\section{Methods}

This research aimed to investigate three main themes: feeling rules, emotion management strategies and death attitudes. There is little research exploring the differences between sets of feeling rules. Due to divergent methods in the literature, it is difficult to make cross-study comparisons of this concept (Wharton 2009). This project responds to a call for more comparative studies (Wharton, 2009).

Qualitative semi-structured interviews were the most appropriate method to capture the nuances of how emotion management strategies form and are operationalized in both professions (Berg and Lune 2012). I recruited participants from Halifax, Nova Scotia and rural southern Ontario by email through purposive sampling methods. Recruiting participants from both provinces was justified by the national standardization of training in both professions. The minor differences in provincial licensing did not affect my research, as I focused on a universal aspect of the professions (the need to manage emotions due to encounters with death) rather than a policy-bound phenomenon.

My data consist of 11 semi-structured interviews with five doctors and six funeral directors. In this study, there were a greater number of female doctors than male (4F: $1 \mathrm{M})$, and conversely, more male funeral director participants than female (4M: 2F). Due to challenges in recruitment, the doctors practiced in a variety of subfields, including palliative care, geriatrics, general practice, emergency, and rural medicine. Each interview lasted approximately 40-60 minutes and focused on the interviewee's experiences with death and emotions in the workplace. My inclusion criteria required participants to have practiced in Canada for a minimum of five years; the participants recruited had between six and 46 years of experience.

I designed my project to meet the ethics standards established by the Dalhousie Research Ethics Board. Participants were provided with all pertinent contact information should they have had any questions or concerns about the interview. With the participant's consent, all interviews were audiorecorded and transcribed. All participants were assigned pseudonyms upon transcription.

I analyzed my data using the qualitative data analysis software Dedoose. I coded all interview transcripts for themes deemed relevant by the literature (feeling rules, emotion management strategies, and death attitudes), as well any new themes that arose from the interviews themselves.

\section{Analysis and Findings}

\section{Contextualizing Professional Death Attitudes}

As previously discussed, societal death attitudes can be characterized by death denial 
(Auger 2007; Aries 1974). If participants of either profession were afraid of death, this did not come up in the interviews, which is an interesting contrast to the existing societal fear. Most participants addressed this fear in others, saying it was likely due to the fact that most people do not know what to expect with death and have a general fear of the unknown. Thus, funeral directors and doctors' familiarity with the technical aspects of death and dying were often cited as a reason for their comfort with their own mortality. Their shared comfort with death was illustrated by Funeral Director Clark's comment that he never found it difficult to deal with dead bodies as it is "just another day at the office."

All participants were quite comfortable discussing death and often spoke of their ability to guide people through the death and dying process as a great privilege and one that must be approached with respect. Both funeral directors and doctors viewed death as extremely significant. This sentiment was clear in Funeral Director Dawson's discussion of how much people are willing to spend on weddings: "You know it always floors me that people will spend fifty grand on a wedding, you know you could be divorced in a couple years and they won't spend eight grand on a funeral, and a funeral is not just a day in your life, it's your entire life in one day." As is evident in the following comment from Dr. Brown, doctors equally valued death:

Walking through death with someone and walking through the birth of a child are the two greatest privileges that you can be part of as a physician or as a human. Right? So I think, in some ways, [l've learned to] recognize death as not something to be feared, but as a part of who we are, part of the human experience.

This reflects a consistent belief among participants that death is a life event equal in importance to birth, an event that should be respected rather than feared.

I discovered several nuances in the way that the doctors and funeral directors conceptualize death. Doctors were interested in defining death, and made reference to the official diagnostic procedures they follow when pronouncing a patient deceased. Doctors also spoke of dying as a process and had varying opinions on its tendency to be prolonged, hinting at a central debate in end-of-life ethics: quality vs. quantity of life.

When funeral directors discussed death, they focused more on the symbolic significance of a funeral and its pivotal role in a family's grieving process. This was illustrated by Funeral Director Edmond when we discussed why people need to have a funeral or similar symbol of closure; he said, "the funeral is really for the living, it's not for the dead." Funeral directors also expressed that their encounters with death have shaped a greater appreciation of life. Funeral Director Almon eloquently conveyed this notion as follows:

It's just important to face [death]. I'm lucky in my profession I'm able to face death reasonably regularly. So, I find it has motivated me in certain aspects of my life to get things done and not procrastinate, and appreciate life a little more because no one's immune.

Several other funeral directors shared this sentiment. Those who did not still explicitly referred to it as an expectation of their profession, as in Funeral Director Clark's comment: "Well it should [make me feel more appreciative], but I don't wake up thinking that really, but yeah it really should. There's times when you really feel and see and think that [...] but that might only last for a little bit and then you kinda get back into your old bad habits or routines."

One shared orientation that emerged was the active role funeral directors and doctors play in death and dying. Dr. Brown illustrated this well, asserting, "I think that's your responsibility [...] A good physician will walk their patient through it, not stand back and observe it." Rather than a distanced role, it is a role that demands care, compassion and immediacy. As a result, both professions have an emotionally demanding orientation towards death in the workplace. 
Dead Weight: The Heavy Emotional Labour of Funeral Directors and Doctors

There are emotional expectations of funeral directors and doctors, a fact well illustrated by Funeral Director Edmond's assertion that "there's a certain care and compassion that goes with the job." As a result, a great deal of emotional labour is required in order to be a "good" funeral director or doctor. When speaking to the emotional nature of the job, Dr. Collins expressed the following:

It's probably the hardest part of the job [...] I remember stressing about the medicine so much and that was dumb. And learning some good self-care strategies really early on, how to prioritize self-care strategies, [that's] probably the smartest thing you can do for yourself to manage this stuff.

This sentiment regarding the difficulty of emotional labour was echoed in many of my interviews, which underscores how pertinent it is to better understand this labour and the processes by which these professionals manage it.

The most common management strategies for both professions were consistent with those identified in the literature, and included but were not limited to engaging with their friends, exercising, using humour, creating clear boundaries between work and home, physically avoiding emotionally laborious situations outside of work, partaking in hobbies and spending time with family (Hochschild 1983; Smith and Kleinman 1989; Mann 2004; Laudermilk 2012). For funeral directors, taking pride in one's profession was the most common emotion management strategy, illustrated by Funeral Director Almon's comment, "[i]n my mind if I do these things well, that helps me deal with that death. Coming back to why I like this job and being fulfilled in it, if I can do a decent job, I feel good about it. In the end I feel like I've done all I can." The primary form of emotion management for doctors was maintaining a scientific orientation towards death. This is exemplified in the following excerpt from my interview with Dr. Collins:

No matter how empathetic you want to be, there are periods where you have to turn into a non...you have to turn into kind of a robot. [...] In the sense that you can't be, you know, taking off the end of someone's finger, which is something you have to do sometimes, and also thinking about all the things they're not going to be able to do if they don't have this finger. You just have to do it. Technical, sometimes the technical trumps the empathetic. It has to, otherwise...empathy is useless without technical skill.

Thus, by focusing on the technical skills and remaining scientifically, albeit robotically, oriented, doctors are able to deal with the associated, potentially distracting, emotions.

The emotional pressure experienced by these professionals is exacerbated by how strongly these individuals identify with their respective careers. For instance, Funeral Director Edmond described funeral direction in the following way, "it's more of a lifestyle than a job because in our situation here it's $24 / 7$ and you're always on call...you just learn to deal with that." Even those who expressed a desire to distance themselves from their professional identity said that they still identify strongly with their career, since it is how others primarily identify them - perhaps particularly in the rural communities in which most of the research participants lived. Funeral directors were often seen as "the death person of the community" (Funeral Director Fletcher) and doctors described being known as "the medical person in the family" (Dr. Atkins). Being viewed through these respective lenses shows that the identity of their job extends far beyond working hours; they are doctors or funeral directors at all times, if not to themselves, then to others. As a result, there is a greater pressure to adhere to the feeling rules of emotional labour, since this labour is so closely tied to the professional's sense of self.

\section{Grave Expectations: Feeling Rules for} Funeral Directors and Doctors

One of the most interesting findings from this research was that identical feeling rules govern the emotional labour of both professions in respect to death. There are two main rules at play: prioritizing the emotions of others and stifling strong emotional responses in oneself. 
Prioritizing Emotions of Others

Putting others' emotions first was the most common of these two feeling rules, and was a notion that arose frequently in all interviews. This is in part due to the way that participants in both professions framed themselves as "service providers", as illustrated by Dr. Brown: "you're there to serve your patient, it's not about what you're feeling. It's about what they're feeling. Their needs come ahead of your needs." Although it is intuitive that the needs of the patient come before the needs of the doctor in a physical sense, this remark was especially interesting as it shows that this extends into the emotional state of the doctor as well. Thus, the patient is a priority in a deeper sense than one might initially assume.

The strength of this rule was evident in Funeral Director Dawson's description of what she used to tell herself at the start of her career about the emotional nature of her job: "Probably just the amount of guilt you'll feel if you're not there for a family [...] I would feel so guilty putting myself first." Her use of "would" was interesting, since it seemed to suggest that this was a hypothetical situation and that she would never actually put herself first in practice.

\section{Stifling Strong Emotions}

The second feeling rule that emerged was that these professionals should not show strong emotions. This generally referred to negative emotions such as stress, frustration or sadness, but it also applied to positive emotions such as relief at not having to engage with an "obnoxious" family anymore once a patient had died. This rule was rationalized in three key ways: emotions as unprofessional, emotions as a burden, and emotions as irrational.

Emotions are regularly framed as unprofessional in the daily work lives of funeral directors and doctors. Dr. Decker described this by saying, "I've occasionally teared up and I'm okay with that. I think it would be inappropriate of me to break down sobbing at the bedside but that's not going to happen because, again, that's that professional thing, that's not my job." This not only exemplifies the professional link with stifling emotions, it also eloquently highlights that this rule applies primarily to strong emotional displays. An "occasional tearing up" is fine, but a stronger display, such as sobbing, violates professional emotional responsibilities.
This tie between being a professional and muting strong emotional displays was evident among funeral directors as well. For instance, Funeral Director Clark provided the following rationale:

I'm able to kind of detach myself from the emotional side of things, and I don't know why or how I can do that but when it's a really tough situation and everybody around you is grieving, this is my job [...] It's not adrenaline, but kinda like a switch that goes on in you and you have to get it done. You have to... they're paying you to provide a professional service and you have to do it.

Further, when I asked whether the stifling of emotions Dr. Brown described occurred often, he replied "yes, but that's when you have to be a professional. And it's not about you, it's about helping them through their problems." This not only shows that the stifling of emotions is related to professional expectations, it also encapsulates the first rule, the prioritization of others' feelings above one's own. Thus, this is a helpful reminder that the two rules are not mutually exclusive.

The stifling of emotions was also rationalized by framing emotion as a burden. Participants often expressed that the presence of their emotions would directly undermine the quality of care they were providing, due to the burden this would place on their patient or grieving family, respectively. For instance, Funeral Director Edmond said, "you have to maintain your composure [...] in order to be a help to the family. You can't have everybody breaking down [...] if you're up there struggling it's no good for anybody." Doctors expressed similar beliefs, such as Dr. Decker when she said, "you don't want to add to the patient's distress."

Emotions were also seen as irrational, with the potential to negatively impact one's ability to provide competent care due to their perceived interference with one's mental clarity. In scientific disciplines, such as medicine or mortuary science, emotions have long been seen as potentially disruptive, with a canonic belief that scientific fact should be kept separate from emotional influence (Peterson 2004). This notion was evident in the reasoning my participants offered for stifling their 
emotional displays. For example, Funeral Director Dawson described this clarity of thought as a key component of being a reliable care provider: "You want to be strong for your families...you have to be their shoulder to lean on or the one that's thinking clearly." This reflects broader North American depictions of emotion, which are challenged in cross-cultural studies showing that emotions are framed as an outcome of social interaction, and are not clearly distinct from thinking in many other areas of the world (Peterson 2004). In other words, emotions are seen as a valued part of rationality rather than a hindrance. Returning to the North American aversion to emotions due to their so-called irrational nature, Dr. Collins provided one potential reason that this attitude is reproduced in medicine, saying "we consistently devalue these things [...] we talk a lot about it but specialties that are heavy in empathy - like psychiatry or family medicine, that kind of thing - those are hugely undervalued from a sort of medical culture perspective." Thus, it is hard to make space for emotions in medicine if their value is not recognized.

\section{Challenging the Rules: "It's Okay to Care"}

It is possible to challenge the described feeling rules. Several participants explicitly wished to distance themselves from the stereotype of the unemotional professional. However, this distancing often provided a perfect illustration of the rules from which they deviate, as seen in the following excerpt from my interview with Dr. Collins:

Earlier in my practice, when I had less experience with death [...] I didn't feel I could cry with patients or I shouldn't, it was unprofessional of me to cry with patients. The burden of my crying is not helping them with their problem. I gotta deal with my own stuff. And that is mostly not...if I feel like I should cry, it's probably okay to cry [emphasis added].

Dr. Collins challenged the idea of being an unemotional professional throughout her interview, often providing similar comments deeming it "okay" to express a given emotion. The use of "okay" in the above excerpt implies that others may not think this is okay, in this case referring to the display of negative emotion. It is of note that this excerpt explicitly refers to the previously discussed feeling rule stifling one's strong emotional responses - and highlights two of its three key rationales, the perceived unprofessional and burdensome nature of emotions.

Another key point of conflict between the feeling rules and the lived experience of the professionals was the risk of dehumanizing both those with whom they work and themselves in order to cope with the heavy emotional demands. For instance, Dr. Brown said, "even when it's a dead body, it's still a person. Treat them like a person. It's okay to be sad." This quote illustrates the tension between humanity and professionalism; doctors are still human and emotions are part of the human experience. The risk of dehumanization is related to the early days of their medical socialization and first experiences with cadavers. Working with cadavers is a transformative experience for many medical professionals, and how it is handled can heavily influence their emotional outlook further on in their careers (Laudermilk 2012; Smith and Kleinman 1989). For instance, Dr. Collins described working with cadavers in the following way:

It was the first piece of socialization to be a doctor in that you have, it's weird right, you had to turn people into their little parts, identify their little tiny nerve or whatever, so you turn people, you dehumanize them completely [...] । remember the afternoon of the first day some dude showed up with a saw, like an electric chain saw type of thing just to crack open the chest cavity, like how dehumanizing is that? For you and the cadaver. It was an incredibly dehumanizing experience.

Further illustrating this tension, when reflecting upon what she would tell herself at the start of her career about the emotional nature of her job, Dr. Atkins insisted, "Let yourself be human."

Conversely, funeral directors were trained in a setting that preserved the humanity of the dead body. This was evident when Funeral Director Clark relayed to me how he learned to 
embalm in school, saying "[t]here's lots of funeral homes that provide [my school] with those bodies, so we never really dealt with cadavers at all. It was real people." This is interesting as it implies that cadavers are not real people, whereas bodies that will have an actual funeral service after the students have completed their work maintain the status of "real people." This speaks to a fundamental difference in the training foci of each profession: doctors dissect, slicing the body into pieces to learn how it works; funeral directors create, aiming - at least in their open-casket work - to make the dead look life-like.

It is of note that all explicit challenges posed to the feeling rules came from my interviews with doctors and mentions of similar challenges to the rules were absent in discussions with funeral directors. This could be due to the relative level of autonomy felt by each profession. Doctors were quite autonomous, and often recounted some solution they had been able to enact when they were in a tough situation. For example, Dr. Collins talked about the frustration of working with families who are trying to convince a dying family member to follow the wishes of the family rather than their own:

I sometimes feel like they're being coerced by their family a little bit. Like they don't want to disappoint their kids or their family or their spouse or whoever. So for those patients, I think the key is to get the families out of the room and talk to [the patient] alone. And I frequently do that. I just say, 'I'm kicking you all out', as lovely as that...and actually the families respond to that.

Conversely, funeral directors were more likely to cite difficulties of this type as part of the job and placed greater weight than doctors on the first feeling rule, putting others' emotions first.

\section{Consequences of Emotional Labour}

As my discussion of the literature suggested, heavy emotional labour in the workplace can result in emotional alienation (Hochschild 1983). Further, workers who perform an abundance of emotion work may lose touch with what they consider to be their true emotions (Hochschild 1983; Sloan 2007). This was evident in Dr. Decker's description of not being able to feel personal emotions following a recent family death: "I wanted to access the fact that this was my aunt, who obviously l've known all my life, and I still don't think I've really accessed that because I went in as the doctor." Since she approached the situation in her "doctor role", her subsequent focus on palliative care and maintaining a scientific orientation directly impeded her ability to engage her personal feelings in the matter. This had occurred a few weeks prior to the interview and she felt she still had not been able to truly experience her personal feelings, exemplifying a very real risk of emotional labour as a required part of one's job.

Another risk of heavy emotional labour is emotional burnout, which can occur when one exceeds one's emotional capacity. Reaching emotional capacity was discussed more frequently among the doctors than the funeral directors. In fact, when I asked members of each profession how they thought the other perceived death, Funeral Director Almon expressed that being a doctor is beyond his emotional capacity, saying, "I don't think I could do that. I know I couldn't do that." However, emotional dissonance was more common among the funeral directors than doctors (Dijk and Brown 2006). For instance, when speaking to the difficulties of experiencing emotional dissonance, Funeral Director Baker recounted the following example:

I was working with somebody and you know, [they were] explaining to me that homosexuality is a disease and it's brought by Satan himself. And in so many workplaces you can say, you know, 'I don't agree with that, go away'. But in my workplace, you say 'Okay, so now let's work with that.' Those types of things.

In this excerpt, a key theme is illustrated: funeral directors felt the need to constantly accommodate, despite the personal challenges this emotion management entails.

Thus, doctors seemed to call upon their emotions more often, risking a maxing out of their capacity, whereas funeral directors were more likely to burn out as a result of frequently 
displaying conflicting emotions. This is likely linked to their respective uses of deep acting and surface acting. Doctors have retrained their emotional response; in other words, they employ deep acting to call upon true emotions. For instance, when speaking to her most recent experience with a dead body in the workplace, Dr. Elm described her emotional response in the following way: "I think it never really changes, it's almost as if you're emotionally primed to have the same reaction every time [...] you have to put on your professional hat, you know, to not tear up or become emotional." Conversely, funeral directors present the expected surface response without necessarily changing what they truly feel on a personal level, and thus are not burning out their personal emotional capacities.

Previous studies have shown that surface acting has detrimental effects on the worker, whereas deep acting is solely positive and often generates a sense of personal accomplishment (Brotheridge and Grandey 2002). However, this is in direct contrast with my findings. I argue that the use of deep acting or surface acting to manage emotions in the workplace is more complex than a simple dichotomy of one being beneficial and the other detrimental. Rather, the heavy reliance on one method over the other can lead the worker towards emotional burnout in two different ways: either by maxing out one's emotional capacity (deep acting) or through the frequent occurrence of emotional dissonance (surface acting). Thus, although both are formed in response to a professional relationship with death, and the emotional labour of these professionals is governed by the same feeling rules, their differing orientations towards death and relative level of autonomy pose different risks towards experiencing emotional burnout.

\section{Implications}

One potential application of this study is informing end-of-life training programs for both professions; perhaps it would encourage the integration of more emotion management classes and workshops. However, most interviewees were highly critical of the possibility of teaching emotion management skills in the classroom. Rather, learning how to manage one's emotions was described to be an individual process, learned primarily through personal experience. For instance, Dr. Brown described her emotion management development in the following way, "[i]t's just an evolution that has to happen [...] [It] can only be experienced." Dr. Collins also identified with the individualized nature developing emotion management methods when she said, "There was definitely this, like, 'you can't talk about this stuff', it was only years later [...] that I could really you know, really kind of process what had happened and how it had been important." This supports previous studies that have demonstrated the privatization and downplay of emotions in medical school (Smith \& Kleinman 1989). By privatizing their feelings in order to appear professional, students believe their peers are simply handling situations better than they are themselves, and refrain from discussing their feelings and related coping mechanisms.

This inclination to mask feelings in the service of professionalism was expressed by funeral directors as well, as illustrated by Funeral Director Fletcher, who said, "[a]t the beginning of the career, [there are] some things that I guess you just deal with on your own and it's something you can't probably talk about with other people that easily, and things that you see and hear are things that you don't forget." This phenomenon of privatization has interesting implications, then, for how management strategies are formed and operationalized; it supports the potential merit of opening up this discussion both among professionals and between professions.

Emotional learning did not always occur individually. Many participants expressed the intimate role that mentorship played in development of their emotion management strategies. For instance, Dr. Brown expressed the importance of mentors when learning to care in all ways: "Mentors are a huge role in learning how to care for people. Well, mentors are a huge role in learning how to love, outside of medicine right? Hopefully you can learn from others' experiences and not have to screw up yourself." An example of what most participants considered to be helpful mentoring was the act of debriefing after stressful events, 
such as for doctors the first time a patient died while they were working. Funeral Director Dawson, who often mentioned her gratitude for the mentorship she had received, illustrated the role of mentoring for funeral directors in the following excerpt from our interview:

Before [my old boss] would do anything, he would say 'this is what I'm going to do.' And it's hard to for us too, once you've been in this business long enough those things become normal to you, so it's hard to remember to tell people that are new, 'this is what's going to happen' so they're not like 'Oh my goodness!' right? And you don't shock them or scare them. [...] He was very relaxed and that kind of stuff probably played into me being pretty good about everything.

Thus, having had a mentor who was careful to always check in and debrief notably contributed to her level of comfort with her emotion management skills.

Further, all participants expressed that learning how to deal with the emotional labour of the job is important, even if they themselves did not identify as someone particularly skilled at this emotion management. One example of this was Funeral Director Clark's remark: "I'm not one to share much of my feelings, but it's healthy to do it." This speaks to the significance of taking care of oneself and one's emotions in jobs that call for high quantities of emotional labour, such as the professions highlighted in this study. As Dr. Decker said, "If you don't look after yourself, you can't look after anybody else." Therefore, it would be helpful to create more space in these professions for emotional debriefing, including discussions of how frequent encounters with death have made these professionals feel.

\section{Conclusion}

\section{"You do not have to be a robot. It's totally okay to cry. It's okay to care." - Dr. Elm}

Emotional labour serves an important societal function; it is desirable to have funeral directors and doctors who are calm and compassionate in the face of death. Thus, emotional labour is a necessary performance, and the processes that make it possible are worthy of study. By exploring the emotion management and death attitudes of these death professionals, I have identified two key rules that dictate how funeral directors and doctors believe they should feel in regard to death: prioritizing the emotions of others and stifling one's own strong emotions. However, these rules can be challenged and do not dictate how all professionals manage their emotions. With these findings, this study contributes to the improved understanding of the processes of emotional labour. Beyond funeral directors and doctors, findings from this study may also be of interest to other death professionals, such as hospice care workers.

In the past, studies of emotional labour in the workforce have focused on a single occupation, rendering it difficult to compare sets of feeling rules between professions (Wharton 2009). Comparative studies such as this one are required in order to further our understanding of both the formation and operationalization of emotion management strategies. I have shown that although similar sets of feeling rules emerge in both medicine and funeral direction, there is great nuance in the meaning they have for each profession. Differences became apparent in terms of how these rules are managed and what the related emotional consequences may be, due to their respective reliance on surface acting and deep acting emotion management strategies. In the future, it would also be helpful to complement existing research with participant observation studies in order to better illuminate the meaning that emotional labour has for individuals in practice (Bianchi et al. 2014).

By presenting the comfortable relationship doctors and funeral directors have with death, this study also hopes to challenge, or at the very least complicate, the often taboo nature of death in contemporary North American society. This is an ambitious and timely endeavour, as in Canada we are seeing recent changes to physician-assisted suicide legislation as well as a general push to demystify what one intensive care unit physician, Dr. Jessica Zitter, identifies to be "society's last taboo" (Tremonti 2017). In a recent $C B C$ article, Dr. Zitter asks readers to consider, "[i]f sex ed exists in high school curriculums, why not death ed?" (Tremonti 2017). To quote my own research participant Funeral Director Almon, when it comes to 
death, "no one's immune." Therefore, why not better prepare the public for the inevitable and open up an overdue discussion? There is no doubt that death is emotional, but studying the emotional labour of these death professionals serves as a fine reminder that these emotions are manageable.

\section{Acknowledgements}

Thank you to my participants; I truly appreciated the time and energy you generously shared with me. I am also thankful for the Sociology \& Social Anthropology department at Dalhousie University, and to the talented social scientists Dr. Radice, Dr. Eramian and Dr. Whelan in particular. I am also indebted to the family and friends who heard, read or discussed this project in its various stages. 


\section{References}

Aries, Phillipe. 1974. "The Reversal of Death: Changes in Attitudes Toward Death in Western Societies." American Quarterly26(5): 536-560.

Auger, Jeannette. 2000. Social Perspectives on Death and Dying. Halifax, NS: Fernwood Publishing.

- - - 2007. Social Perspectives on Death and Dying, 2 nd ed. Black Point, NS: Fernwood Publishing.

Bailey, Tara. 2010. "When Commerce Meets Care: Emotion Management in UK Funeral Directing." Mortality 15(3): 205-222.

Berg, Bruce \& Howard Lune. 2012. "A Dramaturgical Look at Interviewing." In Qualitative Research Methods for the Social Sciences, 105-128, 135-157. Boston: Pearson.

Bianchi, Alison J., Alexander M. Ruch, Micheal J. Ritter, and Ji Hye Kim. 2016. "Emotion Management: Unexpected Research Opportunities." Sociology Compass 10(2): 172-183.

Brotheridge, Celeste, and Alicia A. Grandey. 2002. "Emotional Labor and Burnout: Comparing Two Perspectives of 'People Work."' Journal of Vocational Behavior 60(1): 17-39.

Dijk, Peter A., \& Andrea Kirk Brown. 2006. “Emotional Labour and Negative Job Outcomes: An Evaluation of the Mediating Role of Emotional Dissonance." Journal of Management \& Organization 12(2): 101-115.

Ekman, Paul. 1982. Emotion in the Human Face (2nd ed). New York: Cambridge University Press.

Freud, Sigmund. 1955. "Our Attitude Towards Death", In The Standard Edition of the Complete Psychological Works of Sigmund Freud, 289-300. London: Hogarth Press.

Glomb, Theresa M., and Micheal J. Tews. 2004. "Emotional labor: A Conceptualization and Scale Development." Journal of Vocational Behavior64(1): 1-23.

Goffman, Erving. (1978). The Presentation of Self in Everyday Life. New York: Double Day Anchor Books.

Gorer, Geoffrey. 1955. "The Pornography of Death." Encounter 5(4): 49-52. 
Hochschild, Arlie. 1979. "Emotion Work, Feeling Rules, and Social Structure." American Journal of Sociology 85(3): 551-575.

1983. The Managed heart: Commercialization of Human Feeling. Berkeley: University of California Press.

Laudermilk, Ryan. 2012. Cadaver Dissection and the Ritual Transformation of Medical Students (Doctoral dissertation). Retrieved from ProQuest Dissertations and Theses database. (UMI No. AAI 1503608).

Mann, Sandi. 2004. '"People-work': Emotion Management, Stress and Coping." British Journal of Guidance \& Counselling 32(2): 205-221.

Mellor, Phillip A., and Chris Shilling. 1993. "Modernity, Self-identity, and the Sequestration of Death." Sociology 27(3): 411-431.

Palgi, Phyllis, and Henry Abramovitch. 1984. "Death: A Cross-cultural Perspective." Annual Review of Anthropology 13(1): 385-417.

Peterson, Alan. 2004. Engendering Emotions. New York: Palgrave MacMillan.

Sloan, Melissa M. 2007. “The 'Real Self' and Inauthenticity: The Importance of Self-concept Anchorage for Emotional Experiences in the Workplace." Social Psychology Quarterly 70(3): 305-318.

Smith, Allen C., and Sherryl Kleinman. 1989. "Managing Emotions in Medical School: Students' Contacts with the Living and the Dead." Social Psychology Quarterly 51(1): 56-69.

Strazzari, Maureen. 2005. "Aging, Dying and Death in the Twenty-first Century." In Second Opinion: An Introduction to Health Sociology 3rd ed., edited by John Germonv, 244-263. Toronto: Oxford University Press.

Thoits, Peggy A. 1989. "The Sociology of Emotions." Annual Review of Sociology 15: 317-342.

Tremonti, Anna M. 2017. "Why an ICU Doctor Says Death Ed is as Essential as Sex Ed in High School." CBC. Accessed April 12, 2017. http://www.cbc.ca/radio/thecurrent/the-current-for-april-11-2017 $-1.4064410 /$

Turner, Victor. 1969. "Liminality and Communitas." The Ritual Process: Structure and Anti-structure. Chicago: Aldine.

Wharton, Amy S. 2009. "The Sociology of Emotional Labor." Annual Review of Sociology 35: 147-165.

c)

This work is licensed under a Creative Commons

Attribution-NonCommercialNoDerivatives

4.0 International License. 